\title{
No Longer Out of Sight, No Longer Out of Mind? How Organizations Engage with Process Mining-Induced Transparency to Achieve Increased Process Awareness
}

\author{
Julia Eggers · Andreas Hein · Markus Böhm $\cdot$ Helmut Krcmar
}

Received: 31 October 2020/Accepted: 15 July 2021/Published online: 1 September 2021

(C) The Author(s) 2021

\begin{abstract}
In recent years, process mining has emerged as the leading big data technology for business process analysis. By extracting knowledge from event logs in information systems, process mining provides unprecedented transparency of business processes while being independent of the source system. However, despite its practical relevance, there is still a limited understanding of how organizations act upon the pervasive transparency created by process mining and how they leverage it to benefit from increased process awareness. Addressing this gap, this study conducts a multiple case study to explore how four organizations achieved increased process awareness by using process mining. Drawing on data from 24 semistructured interviews and archival sources, this study reveals seven sociotechnical mechanisms based on process mining that enable organizations to create either standardized or shared awareness of sub-processes, end-to-end processes, and the firm's process landscape. Thereby, this study contributes to research on business process management by revealing how process mining facilitates mechanisms that serve as a new, data-driven way of creating process awareness. In addition, the findings indicate that these mechanisms are influenced by the governance approach chosen to conduct process mining, i.e., a topdown or bottom-up driven implementation approach. Last, this study also points to the importance of balancing the social complications of increased process transparency and awareness. These results serve as a valuable starting point
\end{abstract}

Accepted after two revisions by the editors of the special issue.

J. Eggers $(\bowtie) \cdot$ A. Hein · M. Böhm · H. Krcmar

Krcmar Lab, Department of Informatics, Technical University of

Munich, Boltzmannstraße 3, 85748 Garching, Germany

e-mail: julia.eggers@tum.de for practitioners to reflect on measures to increase organizational process awareness through process mining.

Keywords Big data analytics · Process mining ·

Sociotechnical mechanisms - Process awareness - Process orientation $\cdot$ Business process management

\section{Introduction}

Organizations nowadays have an abundance of data at their hands, originating from various sources inside and outside the firm (Jones 2019), that provide them with novel capabilities for analyzing internal and inter-firm processes. Taking advantage of the vast amount of data, process mining has received increased attention over the last decade from both researchers and practitioners. Process mining is a big data analytics (BDA) technique for discovering business processes, checking process conformance, and enhancing process models (van der Aalst 2016). By analyzing large amounts of event data readily available in contemporary information systems, process mining reveals business processes as they are executed (van der Aalst 2016), generates process transparency, and thus enables firms to rapidly adapt to quickly changing business requirements (vom Brocke and Mendling 2018). The success of German process mining start-up Celonis-valuated at \$ 11.1 billion as of June 2021 (Konrad 2021) - is indicative of process mining's practical relevance, and a predicted three- to four-fold increase in the current $\$ 160$ million process mining market suggests its continued importance (Kerremans 2019).

Process mining is expected to facilitate process optimization by creating unprecedented transparency of business processes (van der Aalst 2016). Formerly, firms relied 
on manual process modeling and the heterogeneous, subjective process knowledge of individuals scattered across the organization to create process transparency (Dumas et al. 2018). Today, process mining creates transparency of a firm's as-is process variations, including less known and less frequent processes, as long as they are recorded in the firm's IT systems (Jans et al. 2014). Thus, process mining constitutes a turning point for many organizations as they become aware of their process variety for the first time (Davenport 2020).

While process awareness is considered the starting point for organizations to shift their focus towards comprehensive process management across organizational silos (Kohlbacher 2010), achieving data-driven process awareness based on process mining has proven difficult for firms. A recent study from Germany reported that even though $80 \%$ of the 360 firms surveyed use process mining with the goal of achieving process transparency and awareness, they face challenges in realizing the expected benefits, for example, due to resistance to transparency and an insufficient process-oriented mode of thinking in the workforce (Reder et al. 2019). This indicates that even though process mining provides the technological potential to create unprecedented process transparency, process awareness does not automatically follow from its use. Instead, organizations still struggle to employ the mechanisms to leverage transparency for process awareness. This observation resonates with recent research that highlights the need to understand how organizations act upon the pervasive transparency created through process mining (Grisold et al. 2020; Mendling et al. 2020) and how they leverage the transparency to benefit from increased process awareness (Eggers and Hein 2020). As process awareness consists of a multi-layered construct that requires a firm to develop a shared process language and understanding (Christiansson and Rentzhog 2019), achieving it with the help of technology should not only be investigated as a merely technical question but instead as a socio-technological phenomenon (Sarker et al. 2019). It is a phenomenon that consists of a technical component, such as the process mining tool, and the social component, such as the organization's individuals and collectives and their relationships and interactions (Sarker et al. 2019) that are inextricably interwoven while achieving technology-enabled process awareness. Nevertheless, thus far, research on process mining has mainly focused on advancing the technological basis (Grisold et al. 2020), while its sociotechnical implications remain largely unknown. We, therefore, set out to study process mining in its sociotechnical context to shed light on how firms engage with the process transparency created from process mining to achieve increased process awareness. Thus, we address the following research question:
RQ: How do organizations engage with the process transparency created by process mining to increase organizational process awareness?

To this end, we conduct an exploratory multiple case study to study process mining as a contemporary phenomenon within its real-world context (Eisenhardt 1989). We choose a qualitative approach as we consider the organizational context (Eisenhardt 1989) in which process mining is applied, such as the industry, the company size, and the process analyzed, to be important for understanding the mechanisms that lead to process awareness. Thus, we study four organizations of different sizes and industry settings that focus on different processes. Drawing on data from 24 semi-structured interviews and archival sources, we reveal seven mechanisms that enable organizations to create process awareness from process mining. Surprisingly, our findings indicate that these mechanisms depend on the governance approach chosen to conduct process mining, i.e., a top-down or bottom-up driven implementation approach.

Our results contribute to research threefold. First, our study contributes to research on business process management (BPM) that highlights the challenges of achieving process awareness (Christiansson and Rentzhog 2019; Dumas et al. 2018) by revealing process mining-enabled mechanisms as a new, data-driven way of creating process awareness. Second, our research sheds light on the hitherto unknown implications of the governance structure of process mining projects (Mendling et al. 2020; vom Brocke et al. 2014) for the mechanisms that allow firms to create and leverage process transparency. Third, our study also points towards the importance of taking measures to balance the social complications of increased transparency (Richards and King 2013). These results serve as a starting point for practitioners to reflect on measures to increase organizational process awareness through process mining.

\section{Theoretical Background}

\subsection{Process Mining}

Based on the multitudes of event data logged in information systems, organizations can derive meaningful insights into process execution, discover process performance problems, and improve the way their business operates (van der Aalst 2016). To this end, process mining leverages event $\operatorname{logs}$ that comprise sequentially recorded events in which each event relates to a specific activity as a step in a business process. Additional information, such as the person executing the activity, the costs related to the activity, and the activity's timestamp, may also be available for analysis (van der Aalst 2016). In summary, firms can use 
process mining to discover process models without prior knowledge of a process, to check for conformance by comparing a priori process models to the event log of the same process, and to enhance existing process models based on information in the corresponding event log of the actual process (van der Aalst 2016).

Since its emergence in the mid-90s (Agrawal et al. 1998), research on process mining has mainly focused on advancing the technological basis by developing more refined algorithms for process discovery and conformance checking (for a detailed review, see Augusto et al (2019)), new methods for event log pre-processing (Mannhardt et al. 2019), and suitable process mining tools (Turner et al. 2012). Recently, a growing body of literature has emerged that recognizes the application of process mining in an organizational context. However, in this regard, the extant literature mainly focuses on the technical perspective of implementing process mining in organizations rather than on the sociotechnical implications of using it in an organizational context. For example, several studies investigate the application of different process mining algorithms in specific domains, such as healthcare (Farid et al. 2019), education (Ghazal et al. 2017), and supply chains (Jokonowo et al. 2018). In addition, extant literature addresses the application of process mining across industries to compare prevailing source systems and techniques (Dakic et al. 2018; Thiede et al. 2018).

Only recently, the first studies emerged to shed light on the sociotechnical implications of process mining, such as the necessary organizational antecedents, for example, a structured project management approach (Mans et al. 2013) and collaborative practices to evaluate the data and analyses (Eggers and Hein 2020), as well as potential managerial challenges (Grisold et al. 2020) when implementing the technology. Yet, these studies are but the beginning as the implications of the pervasive transparency created from process mining still remain unclear (Grisold et al. 2020), in particular in the light of emerging challenges, such as the fear of control and privacy loss (Grisold et al. 2020; Mendling et al. 2020).

\subsection{Process Awareness}

The concept of process awareness is rooted in research on organizational process orientation (Davenport and Short 1990; Hammer and Stanton 1999) and refers to the notion of employees being aware of how they perform theiroften subconscious-routines, how their work is embedded in the overall process, and how their actions are linked to internal and external stakeholders (Leyer et al. 2018). Therefore, process awareness is considered a critical antecedent for organizations to shift their focus from managing and optimizing functional silos to achieving comprehensive process optimization across functional and departmental boundaries (Dumas et al. 2018).

Essentially, business processes can occur, and thus, be managed at three different organizational levels. Stemming from Taylorism, organizations traditionally focused on optimizing inter-individual processes, that is, sub-processes that are executed within small workgroups and departments (Davenport and Short 1990). However, in their seminal article on process orientation, Davenport and Short (1990) urged organizations to orient process management towards inter-functional processes, that is, processes that are carried out within the organization, but across functional or departmental units, and inter-organizational processes, that is, processes that are occurring between two or more organizations. Thereby, organizations achieve an orientation towards end-to-end processes, that is, "processes that interface with customers and suppliers of the organization" (Dumas et al. 2018, p. 49). Only through process orientation can firms optimize their increasingly interrelated, collaborative, and flexible processual reality (Davenport and Short 1990; Dumas et al. 2018). While process orientation requires various substantial organizational changes, such as a process-oriented structure, roles (Christiansson and Rentzhog 2019; Danilova 2019), and culture (van Assen 2018), there is consensus that the first step towards process orientation is the inward look (Kohlbacher and Gruenwald 2011). Only if the firm and its members are fully aware of the current process landscape with all variations and interrelations will they be able to define and implement organizational changes (Kohlbacher 2010).

Yet, achieving process awareness is a challenging endeavor. First, creating the necessary transparency on business processes is difficult as processes and actions are often not named, the quantity of processes and variations is unknown, the processes are not documented in maps or charts, process boundaries are not clearly defined, and process knowledge is highly fragmented across the organization (Corallo et al. 2010; Kohlbacher and Gruenwald 2011). Second, to effectively identify and communicate business processes, employees require a shared process understanding (Christiansson and Rentzhog 2019). However, creating a shared process understanding is difficult as employees rely on their individual perceptions of processes and might lack a shared language to refer to processes and activities (Dumas et al. 2018; McCormack and Rauseo 2005).

To this end, research on the overarching field of BPM has yielded several methods for creating process awareness. Traditionally, BPM provides interview-based and workshop-based process discovery methods (Dumas et al. 2018) that rely on process experts eliciting and capturing process knowledge from domain experts. Even though 
these approaches provide rich insights and the setting to develop a shared process understanding, they are timeconsuming and rely on the often limited ability of domain experts to recall the entirety of their working routines (Rosemann 2006; Seethamraju and Marjanovic 2009). Therefore, these approaches are complemented by evidence-based process discovery methods, such as analyzing existent process documentation or observing process operators (Dumas et al. 2018). All methods, however, are based on subjective perceptions of a process. The resulting process models can be distorted to be incomplete, outdated or reflect the process view of individual experts (Malinova and Mendling 2018) who are usually very knowledgeable regarding their own tasks but lack an understanding of the overall process context they are embedded in (Dumas et al. 2018; McCormack and Rauseo 2005). Therefore, creating and communicating transparency on inter-functional and inter-organizational processes is still considered a challenge (Corallo et al. 2010; Leyer et al. 2018). With the advent of automated, evidence-based process discovery techniques, such as process mining, the opportunity emerges to create organizational process awareness that is no longer dependent on individual perceptions (Mendling et al. 2020). However, we still lack an understanding of how organizations engage with the transparency created from process mining (Grisold et al. 2020) and how the technology facilitates the emergence of process awareness (Eggers and Hein 2020).

\section{Methodology}

\subsection{Research Design}

Studying the mechanisms that lead organizations to create increased process awareness from process mining involves a complex and context-sensitive research setting. We, therefore, considered a qualitative case study approach to be particularly suitable for investigating such a novel and complex phenomenon (Dubé and Paré 2003; Yin 2014). In particular, we chose an exploratory, multiple case study research approach aimed at building theory (Eisenhardt 1989) since we still lack an understanding of how organizations engage with transparency through process mining to achieve process awareness (Grisold et al. 2020). To develop a theory of how organizations create process awareness from process mining, we entered the field with no prior theory and hypotheses to avoid bias and limiting the findings (Eisenhardt 1989). We selected four cases to study the respective organization's process of using and creating process awareness from process mining as the unit of analysis (Dubé and Paré 2003). By studying multiple cases, we could explicitly consider the specific usage contexts of process mining, enabling us to deepen our understanding and explanations for the observations made (Miles and Huberman 1994). Thus, we adopted a theoretical replication logic as we predicted contrasting results from the cases for anticipatable reasons due to the case context (Eisenhardt and Graebner 2007). Therefore, the choice of the four cases was based on a theoretical sampling approach using the principles of similarity and contrast (Miles and Huberman 1994) so that the chosen cases were considered useful in providing rich insights into the research question (Eisenhardt 1989).

We ensured similarity across the cases regarding the critical aspect of our research question, i.e., process mining in an organizational context. Therefore, we selected organizations that had used process mining for at least four years to ensure they had implemented several process mining projects, from requirements analysis to implementation to evaluating and using the results. In this way, we could account for the fact that technical issues that may initially complicate the implementation of process mining (van der Aalst et al. 2011) do not obscure the mechanisms that lead to process awareness. However, we presumed these mechanisms vary depending on (1) the specific process and industry context for which process mining is applied by the organization and (2) the company size and structure. We argue that (1) the specific process and industry contexts, such as an internal production process or a cross-organizational purchasing or customer process, are important since they might impact how the stakeholders involved in a process generate a shared process awareness from process mining. For example, internal process stakeholders might already share a specific common process language that external process stakeholders lack, thus requiring different mechanisms to create process awareness. We also aimed to consider industry-specific characteristics, such as machine-intensive, rigid processes in production, or flexible, customer-centric processes in the service industry. Second, we consider (2) the company size and structure to be influential on mechanisms for creating process awareness from process mining. For example, the members of a medium-sized, local organization might be more familiar and closely connected to use process mining jointly. In contrast, a large, multinational organization might need to establish mechanisms dedicated to enforcing the collaboration on process mining across departments and locations. Table 1 gives an overview of the four selected cases.

\subsection{Data Collection}

To ensure construct validity, we used multiple sources of evidence and engaged in data triangulation (Yin 2014). We conducted 24 semi-structured, in-depth expert interviews 
Table 1 Overview of the case studies

\begin{tabular}{|c|c|c|c|c|c|}
\hline $\begin{array}{l}\text { Pseudonymized } \\
\text { name }\end{array}$ & Industry & $\begin{array}{l}\text { Years of process } \\
\text { mining experience }\end{array}$ & $\begin{array}{l}\text { Company size } \\
\text { (based on } 2019 \\
\text { revenue) }\end{array}$ & $\begin{array}{l}\text { Number of } \\
\text { employees (as of } \\
2020 \text { ) }\end{array}$ & Process mining focus \\
\hline ManuCorp & $\begin{array}{l}\text { Electrical equipment; } \\
\text { Multinational } \\
\text { corporation }\end{array}$ & 8 & $>€ 28$ billion & $>100,000$ & $\begin{array}{l}\text { Internal processes (internal } \\
\text { supply chains) }\end{array}$ \\
\hline DistriCorp & $\begin{array}{l}\text { Wholesale; German } \\
\text { company }\end{array}$ & 6 & $>€ 0.1$ billion & $<200$ & $\begin{array}{l}\text { Cross-organizational processes } \\
\text { (procurement and warehousing) }\end{array}$ \\
\hline PensionCorp & $\begin{array}{l}\text { Financial services; } \\
\text { Dutch company }\end{array}$ & 4 & $>€ 0.8$ billion & $<3,000$ & $\begin{array}{l}\text { Cross-organizational processes } \\
\text { (customer journey) }\end{array}$ \\
\hline AutoCorp & $\begin{array}{l}\text { Automotive; } \\
\text { Multinational } \\
\text { corporation }\end{array}$ & 4 & $>€ 100$ billion & $>120,000$ & $\begin{array}{l}\text { Internal processes (development } \\
\text { and production) }\end{array}$ \\
\hline
\end{tabular}

$€=$ Euros

(Myers and Newman 2007) across the four organizations, with a total duration of over $19 \mathrm{~h}$, and collected archival data, such as case studies, blog entries, videos, and newspaper articles. An overview of the interviews and the collected archival data is displayed in Table 2.

For the expert interviews, we developed a semi-structured interview guideline with open-ended questions included in Appendix A. As we aimed to unravel the mechanisms that lead to process awareness through process mining-induced transparency, we addressed the following areas of inquiry: why and how the organization implemented process mining, the mechanisms and factors that enabled the implementation and use, and the outcome, i.e. transparency and process changes, that they achieved from applying process mining to specific processes. We aimed to represent a "variety of voices" (Myers and Newman 2007). Thus, we interviewed various roles related to process mining use across the organizations, including data scientists, IT experts, process owners, and executive managers. As each of the four cases has a different focus of process mining analyses, we ensured to include business experts from the departments involved in the process mining analyses, such as production or procurement. Beyond the interview data, some informants were willing to give a demonstration of how they use process mining so we could gain deeper insights on how they analyze their processes and what findings they obtain. Our sources for archival data included the companies' websites, websites of process mining vendors and process mining consulting companies, and peer-reviewed as well as (online) media articles pertaining to the firm's process mining use. Finally, to ensure reliable results, we maintained a chain of evidence and developed a case database (Yin 2014).

\subsection{Data Analysis}

To conduct the data analysis, we engaged in within-case and cross-case analysis (Eisenhardt 1989), following a grounded theory coding process (Glaser and Strauss 1967). This approach consists of the open coding of first-order concepts from the qualitative data that describe the phenomenon of interest, i.e., how transparency through process mining leads to organizational process awareness. We assigned the open codes at the level of the within-case analysis, that is, we coded and analyzed each case individually. Then, we formed the second-order constructs using axial coding to establish the interrelationships between the codes. To this end, we compared first-order codes across cases to recognize cross-case patterns and interrelations. In the last step, we conducted selective coding to aggregate dimensions that describe relating second-order constructs (Gioia et al. 2013).

Starting with open coding, we used a line-by-line coding approach to extract factors and mechanisms that might be relevant for creating process awareness through process mining for each case. We adhered closely to the informants' and archival sources' language and developed over 400 open codes. We discussed these open codes and aggregated codes that were clearly redundant, for example, "discussing analyses with other departments" and "crossdepartmental collaboration to evaluate process mining". Our final set comprised 389 codes reflecting how, why, and to which result each of the firms used process mining. Next, we discussed the set of open codes to find similarities and differences among the codes and assemble them into more theoretical categories (Gioia et al. 2013). While constantly comparing the data and emerging codes, we aggregated the first-order codes into 11 second-order themes that are specific to the organization's chosen governance approach (i.e., a top-down or bottom-up approach). 
Table 2 Overview of the interviews and archival data sources

\begin{tabular}{|c|c|c|c|c|}
\hline $\begin{array}{l}\text { Pseudonymized } \\
\text { company name }\end{array}$ & Position of informant & $\begin{array}{l}\text { Years of process } \\
\text { mining experience }\end{array}$ & $\begin{array}{l}\text { Duration of } \\
\text { interview (hh:mm) }\end{array}$ & $\begin{array}{l}\text { Number \& type of archival sources collected for the } \\
\text { case }\end{array}$ \\
\hline \multirow[t]{5}{*}{ ManuCorp } & $\begin{array}{l}\text { Head of Process } \\
\text { Analytics }\end{array}$ & 4 years & $00: 35 \& 00: 45$ & \multirow[t]{5}{*}{$\begin{array}{l}6 \text { (case study, presentation, videos, blog entry, } \\
\text { newspaper article) }\end{array}$} \\
\hline & $\begin{array}{l}\text { Regional Process } \\
\text { Mining Manager }\end{array}$ & 2 years & 00:54 & \\
\hline & Regional CIO & 8 years & 00:58 \& 01:02 & \\
\hline & IT Project Manager & 3 years & $00: 32$ & \\
\hline & Sales Manager & 4 years & $00: 51$ & \\
\hline \multirow[t]{6}{*}{ DistriCorp } & $\begin{array}{l}\text { Chief Executive } \\
\text { Officer }\end{array}$ & 6 years & 01:10 & \multirow[t]{6}{*}{$\begin{array}{l}9 \text { (presentations, videos, blog entries, case study, } \\
\text { demonstration during interview) }\end{array}$} \\
\hline & Chief Process Officer & 6 years & 01:02 \& 00:39 & \\
\hline & $\begin{array}{l}\text { Process Mining } \\
\text { Developer }\end{array}$ & 3 years & 00:53 & \\
\hline & $\begin{array}{l}\text { Process Owner } \\
\text { Procurement }\end{array}$ & 4 years & 01:02 & \\
\hline & $\begin{array}{l}\text { Procurement } \\
\text { Controller }\end{array}$ & 4 years & $00: 59$ & \\
\hline & $\begin{array}{l}\text { Process Manager } \\
\text { Procurement }\end{array}$ & 6 years & 00:52 & \\
\hline \multirow[t]{4}{*}{ PensionCorp } & Data Scientist & 2 years & $00: 42$ & \multirow[t]{4}{*}{7 (case studies, newspaper articles, blog entry) } \\
\hline & $\begin{array}{l}\text { Head of Customer } \\
\text { Analytics }\end{array}$ & 4 years & $00: 54$ & \\
\hline & Head of Analytics & 4 years & 00:34 \& 00: 29 & \\
\hline & $\begin{array}{l}\text { Project Manager } \\
\text { Customer Processes }\end{array}$ & 3 years & $00: 47$ & \\
\hline \multirow[t]{5}{*}{ AutoCorp } & $\begin{array}{l}\text { Project Manager } \\
\text { Change Management }\end{array}$ & 2.5 years & $00: 45$ & \multirow[t]{5}{*}{$\begin{array}{l}7 \text { (presentations, video, case study, newspaper } \\
\text { articles, demonstration during interview) }\end{array}$} \\
\hline & $\begin{array}{l}\text { Process Owner } \\
\text { Development }\end{array}$ & 1.5 years & $00: 48$ & \\
\hline & $\begin{array}{l}\text { Process Mining } \\
\text { Developer Production }\end{array}$ & 3 years & 00:51 & \\
\hline & $\begin{array}{l}\text { Process Mining } \\
\text { Developer }\end{array}$ & 3 years & $00: 52$ & \\
\hline & $\begin{array}{l}\text { Head of Process } \\
\text { Mining }\end{array}$ & 3 years & $00: 42$ & \\
\hline
\end{tabular}

The second-order themes reflect mechanisms and moderators that enabled the firms to achieve different forms of process awareness from process mining. In the final phase, we distilled the second-order themes into aggregate dimensions and assessed the relationships among the identified themes (Gioia et al. 2013). As a result, we obtained six aggregate dimensions that represent the different forms of process awareness achieved by using process mining, depending on the governance approach. The resulting data structure, representative quotes, and archival entries are displayed in Appendix B.

\section{Results}

The multiple case study yielded insights into how the four organizations implemented and used process mining to achieve process transparency and increased process awareness. In the following, we describe the process that emerged for each firm, from its initial situation before using process mining to the mechanisms for using the technology to generate process transparency and the outcomes achieved that contributed to the firm's path towards process awareness. 
4.1 ManuCorp: Process Mining for Internal Supply Chains

\subsubsection{Situation}

Before ManuCorp first introduced process mining in 2013, the multinational organization faced a highly decentralized process landscape that was managed based on observational evidence and lacked clear responsibilities for end-toend processes.

As the internal supply chain processes are the backbone of the firm's production business, realizing synergies in their supply chains has always been of major importance to ManuCorp. However, despite the close interdependence between the divisions through supplier and customer relationships, responsibility for process design and optimization remained with each division. As a consequence, the more than 50 ERP systems implemented throughout the corporation "are all individually configured per division. So, each division decides what their processes look like and how they use the systems" (Head of Process Analytics). The resulting internationally fragmented process landscape was managed locally by each division. However, ManuCorp lacked the database and mechanisms for creating awareness of end-to-end processes across divisions, for example, from customer order via production to delivery. Even though everybody had " $a$ bad feeling that things were not going well, we did not know what the problem was", as a regional CIO explained. Instead, whenever a division faced process complications, such as late deliveries, the responsible division manager brought together the department leaders, and then "everybody started to argue and was trying to show that it was not their department's fault" (Head of Process Analytics). The divisions tried to substantiate the claims with key performance indicators (KPIs), such as the rate of on-time delivery (OTD). However, these had to be calculated manually using data from the ERP systems. In addition, the KPI definition varied from department to department.

\subsubsection{Standardized Monitoring of Sub-Processes}

To encounter the situation of the locally managed process landscape based on individually calculated process KPIs, in 2013, ManuCorp's executive management introduced process mining to monitor the firm's processes and standardize process reporting. The international roll-out was directed in a top-down approach by the management, who decided on standardized analyses to be used in each division. In particular, every division was now required to use process mining to monitor their sub-processes, such as local warehousing and sales processes, in terms of OTD. To this end, a process mining center of excellence $(\mathrm{CoE})$ was established to support the divisions in implementing the analyses and to provide data literacy training for employees. Yet, although the roll-out was intended to enable more than 3,000 process mining users across the organization, the workforce showed resistance to adopting the new technology, as a regional process mining manager noted: "Using process mining to measure the OTD became mandatory, and many people felt taken by surprise and overwhelmed by the data complexity." In addition, regional managers perceived process mining "as a threat" that would reveal their division's processes and thereby also expose all weaknesses. To expedite the still hesitant adoption, ManuCorp's management incentivized regional managers financially to adopt and promote process mining usage within their divisions. Thus, the division's OTD performance became part of the regional manager's compensation, and process mining was recommended to analyze and improve the KPI. While these measures established process mining for the standardized monitoring of local sub-processes, ManuCorp's management also expected the divisions to increasingly use process mining autonomously as an exploratory tool for detecting unknown process weaknesses. However, the exploratory use did not ensue as "the majority [of employees] just takes a look at the OTD because they feel it is yet another monitoring tool they have to use. So, they do not explore and reflect on the reasons underlying this KPI" (Regional Process Mining Manager).

\subsubsection{Standardized Monitoring of End-to-End Processes}

While process mining allowed for standardized monitoring of the divisions' sub-processes, ManuCorp's management noticed the persistent lack of monitoring across end-to-end processes. They suspected the underlying reason was the lack of responsibility for end-to-end processes. Therefore, new process owner positions were created that were in charge of "end-to-end processes across divisional boundaries and who have the power to summon all process stakeholders to analyze the process with process mining and decide on changes" (Sales Manager). The process owners implemented standardized analyses together with the representatives from the divisions to create and communicate end-to-end process transparency. Cooperation with other divisions, for example, enabled one process owner to leverage the aggregated data from factory sites, distribution centers, and the sales team to analyze the leadto-sales process in a cross-divisional analysis.

\subsubsection{Aggregating Knowledge of the Process Landscape}

While the standardized monitoring of sub- and end-to-end processes led to increased transparency of ManuCorp's 
process landscape, the newly gained knowledge remained fragmented across divisions and process owners. Therefore, a governance board was established to provide the divisions, represented by their division managers, and process owners with a space to exchange information and insights from process mining:

We discuss how processes could be changed based on the process mining analyses, and we define the scope for new analyses, for example, how do we measure global processes? How can we analyze processes across divisions? (Head of Process Analytics)

Thus, the board served as an exchange platform that enabled divisions to reflect their findings within the organization-wide context and thus, to integrate regional process knowledge on a global level. The resulting aggregated, standardized process knowledge was then shared by the managers with their divisions. To further enable the aggregation of process knowledge from a technical perspective and to provide a combined database for process mining, a centralized data lake was established incorporating data from enterprise systems across the organization, such as ERP and CRM systems.

\subsubsection{Democratizing Knowledge of the Process Landscape}

The previous measures facilitated the aggregation of standardized process knowledge across the global process landscape. Still, to operational employees, global process knowledge was available only through their managers or process owners who participated in the governance board. To democratize access to aggregated process knowledge and encourage employees' engagement in the firm's business process management, ManuCorp recently introduced a central process mining platform. The platform was designed to "[store] all processes and interrelations of processes with their corresponding process mining analyses. Today, every employee can access the platform and point out process improvements" (Sales Manager).

\subsubsection{Outcomes}

The top-down driven use of standardized process mining analyses enabled ManuCorp to increase process awareness regarding sub-processes, end-to-end processes, and the global process landscape. Based on the awareness, process changes at all levels were defined and implemented.

On the sub-process level, individual divisions used the standardized OTD analyses to achieve awareness of subprocesses and measure their performance with standardized KPIs. For example, one division's sales department became aware of their high rates of unnecessary price changes, which caused subsequent production delays, and therefore, decided on a new price management strategy.

On the end-to-end process level, ManuCorp's newly appointed process owners used process mining to create end-to-end process awareness and, thus, realized end-toend process synergies. Taking the example of the crossdivisional lead-to-sales process analysis, the responsible process owner found that the reason for late customer deliveries was unnecessary price coordination between some divisions involved in the process. Thus, the process owner defined a standardized approach to price coordination across the divisions.

Process awareness of the global process landscape emerged from two sources. First, the governance board enabled division managers to share their regional process knowledge and gain awareness of process interrelations on the global level. For example, through the governance board, a regional CIO detected process synergies between logistics centers, so that he decided to merge several warehouses into one strategically located shipping point. Second, as a result of the central process mining platform, access to process knowledge was democratized across divisions and hierarchies, giving all ManuCorp employees equal opportunities to know, reflect and potentially improve the firm's process landscape.

\subsection{DistriCorp: Process Mining for Procurement and Warehousing}

\subsubsection{Situation}

DistriCorp, as a wholesaler, is dependent on its efficient procurement and warehousing processes. However, before the medium-sized organization first introduced process mining in 2014, it was challenged by stagnating improvement of throughput times in the warehouse. This situation was complicated by a lack of awareness and responsibilities for optimizing end-to-end processes.

Even though DistriCorp had focused on optimizing its warehousing processes, for example, by automating the picking of goods, the organization faced the situation where "warehouse throughput times had been optimized to the limit, but we did not know why we were still losing time before shipping orders" (Chief Process Officer). The warehouse managers at DistriCorp suspected that the reason was the purchasing department that delayed the order of goods. In contrast, the purchasing department believed the sales department was the originator by forwarding incorrect data in the purchase order. As the CEO describes it, they "experienced finger-pointing due to the lack of process awareness between departments" since they missed the database and mechanisms to substantiate their suspicions with facts. The situation was further 
complicated as the organizational structure lacked end-toend process owners who accounted for processes across departmental boundaries.

\subsubsection{Standardized Monitoring of Sub-Processes}

In 2014, DistriCorp introduced process mining as a technology to increase efficiency in the firm's procurement and warehousing processes. The implementation was led by the management in a top-down approach. To this end, a process mining expert team was established, consisting of an analytics expert, the newly appointed Chief Process Officer (CPO), and the firm's Chief Executive Officer (CEO). The expert team decided on KPIs, such as automation rates and OTD, and standardized process mining analyses to be implemented on the firm's core business processes, such as procurement and warehousing. However, even though the workforce received data literacy training to comprehend process mining, they were hesitant to adopt:

"I had the feeling that I had to put my cards on the table and everybody would see if something is going wrong. Many people were afraid that they would get into trouble if something negative surfaced." (Process

Owner Procurement)

To resolve concerns about supervision, all personal information was anonymized in the database, and the executive management followed a clear communication strategy to assure that analysis results would not be used to disadvantage the departments. In addition, DistriCorp's executive management strived to increase the adoption of process mining within departments by adapting process mining to the needs of operational employees. Together with the process mining provider, DistriCorp developed a new "control function" of the process mining software that alerted operational employees of any unusual incidents within their sub-process, such as a delivery that is late to arrive. As the CPO pointed out, the "employees immediately experienced the added value for their individual process, and they use it every day now". However, the new feature led to employees only attending to the notifications but not using the tool's capability to explore processes, also beyond their department boundaries, due to "perceiving it as overwhelming". The CPO suspected that the reason for this was that employees, except for the expert team, had not been involved in the design and implementation process. Thus, while the individual departments intensified the use of the "control function" to monitor pre-defined irregularities within their sub-processes, the exploratory use of process mining to detect root causes remained absent.
4.2.3 Aggregating Knowledge within and across End-toEnd Processes

However, it soon became clear that the root causes for process problems could only be identified by analyzing end-to-end processes:

"[...] we need to develop process mining analyses that strongly question departmental boundaries. Why should the customer care if our sales department does a great job of processing the order, but it's stuck in the warehouse?" (CEO)

Therefore, the management created the new role of a CPO in charge of supervising all end-to-end processes. Thereby, the CPO became the central authority to aggregate process knowledge within and across end-to-end processes. To this end, the CPO was responsible for connecting with the representatives from the departments, who were monitoring sub-processes with process mining. The CPO engaged the departments to synthesize local process knowledge, identify end-to-end process improvement opportunities, decide on process changes, develop a common global process understanding, and communicate these findings top-down to the departments. Thereby, DistriCorp also became aware of cross-organizational process interrelations. For example, they leveraged internally available ERP procurement data to understand the impact of supplier behavior on procurement performance.

\subsubsection{Outcomes}

The top-down driven use of standardized process mining analyses at DistriCorp resulted in increased process awareness on the level of sub-processes, end-to-end processes, and the global process landscape. Based on the awareness, the CPO, together with representatives from the departments, decided top-down on process changes.

First, awareness of the sub-process level emerged as the new "control function" augmenting DistriCorp's process mining software notified operational employees of irregularities within their sub-processes. For example, purchasing employees were now alerted that "the delivery date is due, but we have not received any order confirmation from the supplier, so we have to send a reminder" (Procurement Controller). Thereby, the individual departments at DistriCorp became more efficient in resolving disruptions within the scope of their sub-processes.

Second, as the CPO encouraged exchanging process mining insights across departments, DistriCorp experienced an increased awareness of and cooperation in end-toend processes. One example of end-to-end process awareness is the collaborative process mining analyses between the warehouse and the sales department at DistriCorp. The 
warehouse department found out they regularly shipped customer orders too late because of the sales department's online shop that allowed customers to enter unverified information. As a result, the sales department modified the online shop to include pre-defined fields to process and ship orders more efficiently.

Third, on a global process level, DistriCorp increased their awareness of the process landscape, also beyond their own organizational borders. For example, by drawing on information provided by their suppliers, such as shipment dates and expected delivery dates, the procurement analyzed the reliability of their suppliers and found out that some suppliers "deliver the goods a few days early, with the best of intentions. However, this has an impact on our warehouse process as we had not expected the delivery, and there is no space in the warehouse" (Process Owner Procurement). DistriCorp shared these insights with the suppliers who adapted their behavior to allow optimal cooperation.

\subsection{PensionCorp: Process Mining for the Customer Journey}

\subsubsection{Situation}

Due to market and regulatory changes, PensionCorp feared stronger competition in the financial services market and, therefore, in 2013, established a strategic program to optimize client-facing processes. However, before PensionCorp implemented process mining in 2016, the program was based on KPIs that were reported individually by departments across the organization and were difficult to interpret as they lacked contextual information.

Even though PensionCorp employed business intelligence (BI) tools to compute KPIs throughout the organization, the results were based "on silos, and we did not have the analytical power to look into the underlying relations" (Data Scientist). In addition, the reported KPIs lacked contextual information, which made it difficult to interpret the data correctly. For example, the term "partner" was referred to differently by individual departments - some defining it as a married couple, while others also subsumed registered partnerships under the term. Interestingly, PensionCorp had already established a data lake combining data from various sources across the firm to standardize and contextualize data. Yet, deriving insights from the data remained difficult since "[we] had one location where all the data was combined. But we did not have the tools to navigate the data and find relationships across all the processes in the systems. Process mining was the answer to that" (Data Scientist).

\subsubsection{Exploring Sub-Processes}

In 2016, PensionCorp's data scientists initiated a local project to investigate how process mining could help to analyze the wealth of event data stored in the central data lake. The data was characterized by high complexity as they originated from many process stakeholders within and outside of the firm. The pension registration process, for example, involves a customer's employer registering him or her for a pension, a firm subcontracted by PensionCorp administering the registration, and PensionCorp receiving the new customer. These sub-processes were supported by four different systems that, however, fed into the central data lake. After an initial analysis of the pension registration sub-process, the team found compliance problems and inefficient communication patterns. PensionCorp's executive management "were surprised by the results, and then it was no question about them continuing with this technology" (Head of Analytics). Thus, they decided to provide process mining services throughout the firm. A CoE was established to support the departments in implementing process mining analyses specific to their needs. Rather than prescribing standardized analyses in a top-down approach, PensionCorp's management chose a bottom-up approach in which departments could request process mining analyses to support their individual goals. To promote the technology within the firm, the CoE team provided data literacy training and inspiration for application scenarios:

“[...] we held community sessions, we talked to people, we demonstrated the technology and what we can do with it. [...] In the beginning, we had to promote it, but now the departments know us, and they come to us. Now, we have even more work than we can take care of." (Data Scientist)

\subsubsection{Exploring End-to-End Processes}

However, while the departments explored sub-processes within their departmental boundaries, it soon became evident that the processual interrelations between departments required the end-to-end analysis and optimization of processes. For example, the ICT department explored why customers were not adopting the self-service channels they provided, such as online forms and websites. While the ICT department investigated how customers were using the self-service channels, they could not identify why some customers refrained from using the services. Therefore, they enriched their process mining analyses with customer survey data on satisfaction with the self-service channels from the communications department. As a result, they found out that for some customer groups, the online selfservice was not providing the necessary features to manage 
all their affairs, and thus, the ICT department adapted the self-service portal. This example illustrates how the departments engaged in the exploratory usage of process mining, which allowed them to identify additional required data sources iteratively. These data sources, often belonging to other departments, provided them with additional pieces to the overall process picture:

"We used to think we had a lot of data within the data lake, but now looking at it with process mining, we see what data we lack, and we add that data." (Head of Customer Analytics)

But while the departments jointly explored end-to-end processes by drawing on data available internally and externally to their departments, PensionCorp's data scientists reported that the organization still lacked process awareness on a global level. Instead, "every department within this company has its own process mining goals and KPIs, and that is hard to manage [for the CoE]. So, we leave the responsibility to conceptualize and work with the analyses to the representatives of the departments" (Head of Customer Analytics). Thereby, the departments autonomously increase their awareness of end-to-end processes that they are embedded in but lack transparency on the overall process landscape.

\subsubsection{Outcomes}

Taking the analysis of the customer journey as a prominent example of the bottom-up driven process mining use at PensionCorp, we observed two prevalent outcomes concerning their awareness of the customer journey on the suband end-to-end process level and improved response to customer needs.

On the sub-process level, PensionCorp achieved increased awareness of inefficient segments of the customer journey. For example, the pension department discovered through the analysis of the pension claim process that they regularly required more time than promised to the customer to process pension claims due to unnecessary rework. Eliminating these unnecessary activities allowed the department to increase efficiency.

In addition, by drawing on internally and externally available data, the departments created awareness of the end-to-end processes they are part of and, hence, identified thus far unknown customer needs. For example, by using customer interaction data internally available at the customer service department, the team was able to create transparency on their customer interaction throughout the customer journey. Thereby, the process analysis revealed that a high volume of customer calls occurred once a year after information documents had been sent out to customers. Complementing these insights with customer survey data showed that "the customers are calling a lot because the documents are not clear enough". The insight was forwarded to the communications department, which then adapted the documents to the customers' needs.

\subsection{AutoCorp: Process Mining for Development and Production}

\subsubsection{Situation}

Having evolved over a century, AutoCorp is characterized by its complex system landscape with over 8,000 different IT systems and its intertwined production processes. Before introducing process mining in 2016, the organization faced increasing competition through new market entrants and thus, strived to increase process efficiency and agility. However, this was complicated by decentralized process management and the lack of awareness of process interdependencies.

Functional areas at AutoCorp, such as production or procurement, have been traditionally autonomous in designing and managing their processes. As a result, however, sub-processes were optimized within departmental silos without considering consequences for other departments, as this example illustrates:

"We would change the painting process, and then, all of a sudden, rework in assembly would skyrocket. However, before we used process mining, no one would notice that connection. There is no communication between these departments. They are located at the same plant, but they are led by different department managers, they have different tasks, and have nothing to do with each other." (Process Mining Developer Production)

The lack of awareness of process interdependencies had particularly strong implications for AutoCorp's change management. Any changes in the product development process require close alignment and adaption in the production process, as changes are costly and complex. Due to the silo-oriented process management, however, AutoCorp's change management struggled to "process hundreds to thousands of change requests every day. [...] We need to understand if these changes align with previous changes and how they affect downstream activities" (Project Manager Change Management).

\subsubsection{Exploring Sub-Processes}

To encounter the lack of knowledge on process interrelations and their consequences, several bottom-up initiatives driven by AutoCorp's departments emerged to investigate process mining as new technology to illuminate unknown 
path dependencies. Upon the first successful initiatives, AutoCorp's executive management then established a process mining CoE to support the departments with collecting process data and implementing process mining analyses addressing their needs. Following a bottom-up implementation approach, the departments were free to define KPIs and analyses as required. For example, the production department analyzed sensor data from assembly to find the root causes for high rework rates in the paint shop.

\subsubsection{Exploring End-to-End Processes}

Supported by the CoE, the departments at AutoCorp engaged in the exploratory usage of process mining, which led to the incremental expansion of the analyses into the end-to-end process context. This development is illustrated by the change management department who initially extracted process data from their central change management system to analyze with process mining. However, "rather than analyzing a process, we tried to analyze a system. We soon realized that the focus was too narrow and that we needed to consider the end-to-end change management process" (Head of Process Mining). The team involved both the development and production side to analyze the end-to-end process. They iteratively identified additional data sources to be included, such as a system for managing error reports from production and another system for managing change requests from customers owned by the development department. However, the integration of additional data was challenging because access to the locally managed data sources was not always approved and required negotiations. Yet, they collaboratively implemented the process mining analyses to achieve transparency on the alignment between their sub-processes, as the process manager from development illustrated:

"We became aware of the predecessor and successor relationships of our departments. For example, we could see how many change requests our [development] project teams submitted to the change management team and how often they ended up not being implemented in production. Then we could discuss reasons for why the information flow failed."

In this way, departments at AutoCorp discovered how they had been neglecting the critical process transitions to other departments and had "focused on being efficient within a silo, but never asked what happens in the next process step" (Project Manager Change Management). However, even though the departments gained transparency on their processual interrelations, their insights remained inaccessible in the broader organizational context, preventing employees from developing process awareness on the global process level. As the Head of Process Mining reported, without a central authority to collect the emerging process knowledge, "the findings persist within the respective departments, but they do not know about each other."

\subsubsection{Outcomes}

Taking the change management process analysis as an example for the bottom-up driven process mining usage at AutoCorp, we observe two outcomes. AutoCorp achieved an increased awareness of sub- and end-to-end processes and, based on the awareness, optimized the intra- and cross-departmental alignment of processes.

On the sub-process level, the departments at AutoCorp leveraged individually conceptualized process mining analyses that created intra-departmental sub-process transparency. For example, the change management department revealed through process mining that they carried out 3,000 different workflows to process change requests. Based on that insight, the department realigned the process by coordinating individual activities more effectively.

On the level of end-to-end processes, the awareness of cross-departmental process interdependencies at AutoCorp increased, driven by the departments' self-organized networking to create cross-departmental process mining analyses. Due to the traditionally self-reliant mode of operation at AutoCorp, process transitions between departments were a blind spot outside the responsibility of any department. However, resulting from the newly gained process awareness through process mining, the departments achieved improved transparency on and alignment of processes across departments. For example, by analyzing the change management process across departmental transitions, the team identified inefficient communication patterns between the development and change management departments that delayed the end-to-end process, which was improved through altered communication rules.

\subsection{Cross-Case Comparison}

Comparing the four cases, it became clear that the organizations developed different mechanisms to implement process mining, increase its intra- and cross-functional use, and achieve process awareness. Depending on the mechanisms, the firms created a shared intra- or cross-functional or cross-organizational process awareness through process mining. By leveraging this process awareness, the organizations derived process changes that advanced their individual company goals. We provide a detailed comparison of the cases in Table 3. Interestingly, we observe that these mechanisms depend not on the process and industry 


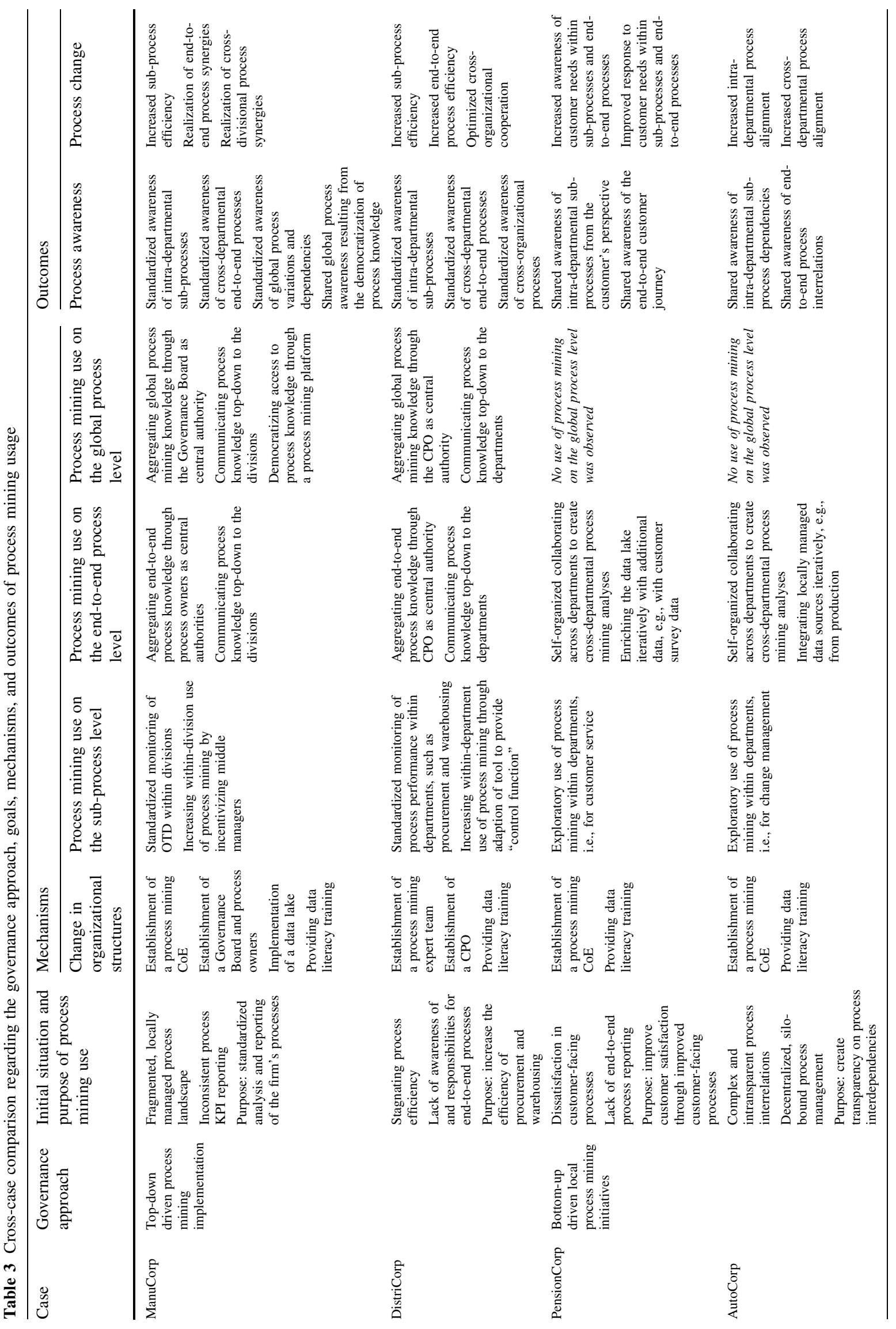


context. For example, we see that ManuCorp, a multinational manufacturer, and DistriCorp, a medium-sized wholesaler, both developed similar top-down driven communication mechanisms to foster process mining use and transparency within and across departments. In contrast, PensionCorp, a local financial service provider, and AutoCorp, a multinational manufacturer, employed similar bottom-up driven exploration mechanisms that iteratively led to process awareness within and across departments. Consequently, the chosen governance approach for conducting process mining plays a decisive role in creating mechanisms that foster process awareness. We will discuss the implications of this observation in the following.

\section{Discussion}

Combining the results of the multiple case study, we observe that firms employ seven mechanisms to achieve increased process awareness through process mining. The resulting process awareness either pertains to the inter-individual process level, that is, stakeholders from one department share awareness of their sub-process, or the inter-functional level, that is, stakeholders across departments share awareness of the end-to-end process. In addition, process awareness on an intra- and interorganizational level can be achieved, that is, organizational stakeholders share awareness of the firm's overall process landscape, including processes across different functions and organizations. The mechanisms leading to process awareness primarily emerge from the firm's process mining governance approach, i.e., bottom-up or top-down, and they are influenced by the firm's capability to facilitate a shared process language, a standardized data infrastructure, and aggregated process knowledge. In the following, we discuss the mechanisms according to the governance approach and then embed them in previous research on process mining and business process management.

\subsection{Bottom-up Exploration Mechanisms Leading to Increased Process Awareness}

The first group of mechanisms to become apparent from the multiple case study relates to the exploratory use of process mining in a bottom-up approach (see Fig. 1). Firms such as AutoCorp and PensionCorp engage in a department-driven use of process mining, meaning that departments are free to define and implement analyses autonomously without requirements imposed on them by the firm's management. As a result, the departments explore their analyses and achieve increased process awareness on the inter-individual and inter-functional process levels.
The first mechanism enables the narrowest form of process awareness on an inter-individual level and emerges from the exploratory use of process mining within one department based on internally available data sources. We have seen this in the example of AutoCorp's production department that explored the root causes for rework in the paint shop based on sensor data. Exploring the sub-process through process mining, the department's employees reflect their own behavior in relation to their peers' actions and thus develop a shared internal awareness of their departmental sub-processes. This awareness-building process is influenced by the fact that they share a common process language. Such a shared process language arises, for example, from the data literacy training offered by each of the companies' process mining CoE. By providing standardized training on understanding process data and conducting process mining analyses, employees develop a common vocabulary to discuss their processes. When evaluating their intra-departmental process mining analysis, a common vocabulary helps create a shared perspective on a jointly performed sub-process. The resulting shared internal process awareness enables the department to define the necessary process changes to overcome identified weaknesses. Consequently, the department internally shares a newly designed routine that is grounded on a shared process awareness facilitated by process mining. However, the shared awareness and the resulting process changes represent a local solution pertaining to the department's sub-process without acknowledging the overarching end-to-end process.

Yet, whenever the local process mining analysis indicates that the root cause for a process weakness is not located within the department's sub-process, the context of the end-to-end process becomes important. Thus, in the second mechanism, the department draws on internal data to explore process steps external to the department so that a shared process awareness on an inter-functional level is achieved. What might sound counterintuitive can be observed in the example of PensionCorp, where the customer service department used customer interaction data available in their systems to develop an understanding of how their clients perceived certain documents provided by the communications department. In this way, one department overcomes its bounded silo thinking by exploring internal process data that shed light on the overarching inter-functional process and, as a result, develops an awareness of the end-to-end process it is embedded in. Consequently, rather than seeking a local optimum, the department strives to infer changes that optimize the overarching end-to-end process.

Alternatively, as a third mechanism, the department draws on external data to explore further phases of the endto-end process so that a shared process awareness on an 


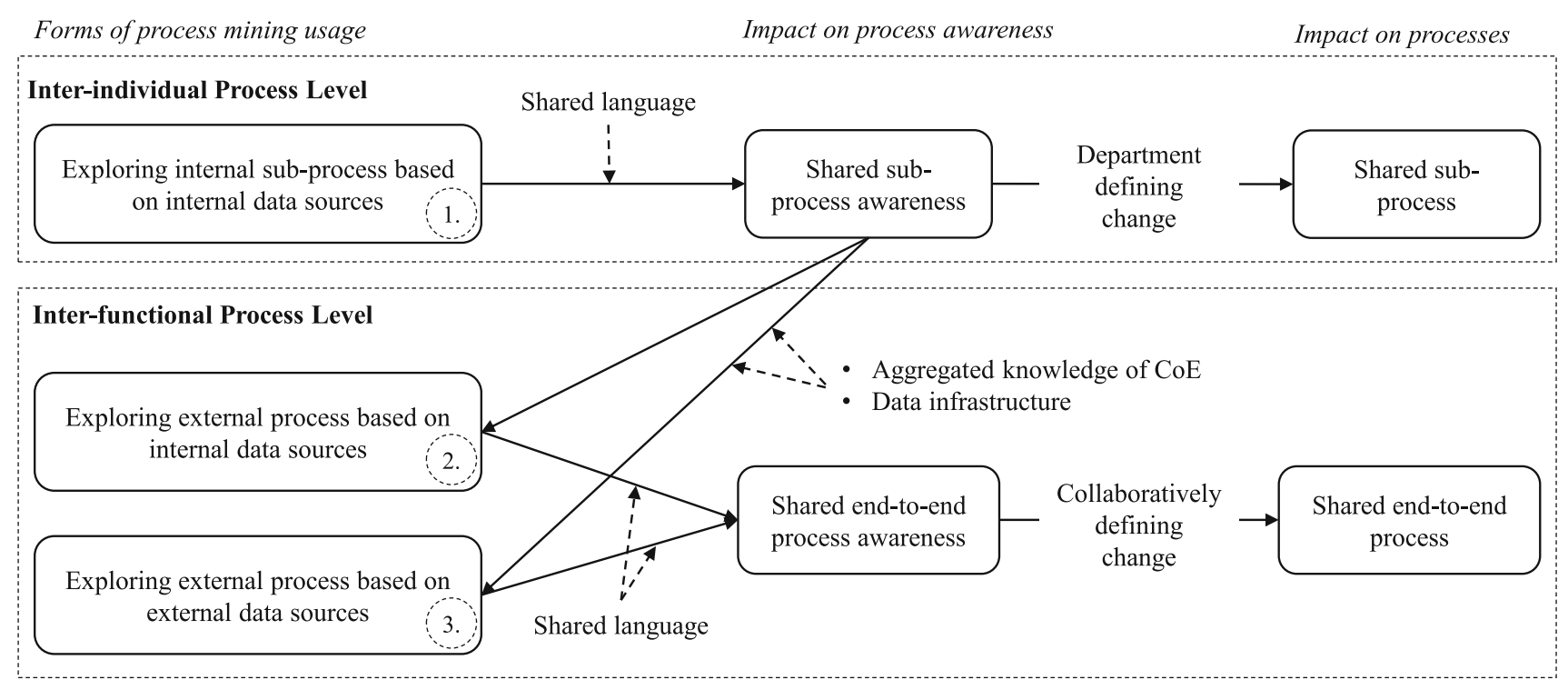

Fig. 1 Mechanisms of bottom-up exploration leading to increased process awareness

inter-functional level is achieved. The external data is provided by other stakeholders of the end-to-end process, such as other departments. Consider as an example AutoCorp, where the change management department initially analyzed their local sub-processes before they recognized the need to include data from other functions, such as development and production, to understand the end-to-end change management process. In the cases we observed, this search process is impacted by the process mining $\mathrm{CoE}$ that has aggregated a wealth of process knowledge through implementation projects in various departments and gives guidance on data sources that could be valuable to explore. Still, it can be challenging to gain access to the data needed, as seen in AutoCorp's example, since they might be under the decentralized governance of individual departments. In addition, data might be available in different formats across systems, presenting a technical challenge. Therefore, a centralized data infrastructure, such as the data lake established by PensionCorp, facilitates the search of and access to (potentially standardized) data. Finally, the joint analysis of process data with stakeholders from the related functions leads to a shared end-to-end process awareness. This joint effort is again facilitated by the shared process language that actors across the organization have acquired from standardized data literacy training. Resulting from the shared end-to-end awareness, process stakeholders collaboratively decide on process changes that reflect not only local optima but an optimum of the end-toend process.

\subsection{Top-Down Monitoring Mechanisms Leading to Increased Process Awareness}

The second group of mechanisms resulting from the multiple case study relates to what we call the monitoring usage of process mining in a top-down approach. Firms, such as DistriCorp and ManuCorp, engage in a management-driven use of process mining, meaning that a central authority is deciding on application areas and standardized analyses. Departments are then required to engage with the standardized analyses to monitor pre-defined process characteristics. This process mining usage enables increased process awareness on the inter-individual level. However, firms pursuing a top-down approach engage in additional mechanisms to increase process awareness on the inter-functional level and the intra- and inter-organizational level (see Fig. 2).

The fourth mechanism enables shared process awareness on the inter-individual process level and resembles the inter-individual mechanism in a bottom-up approach. Contrary to a bottom-up approach, however, departments must use standardized process mining analyses in a topdown approach. Therefore, rather than engaging in autonomous exploration, the departments monitor assumedly relevant aspects of a process. The standardized investigation of known process problems can be of great value, as demonstrated by ManuCorp. By establishing a standardized OTD definition and providing appropriate training across the organization, departments used process mining to internally develop a standardized process awareness and infer necessary process changes to optimize their subprocesses. However, the other side of the coin is the lack of exploration that potentially reveals previously unknown 


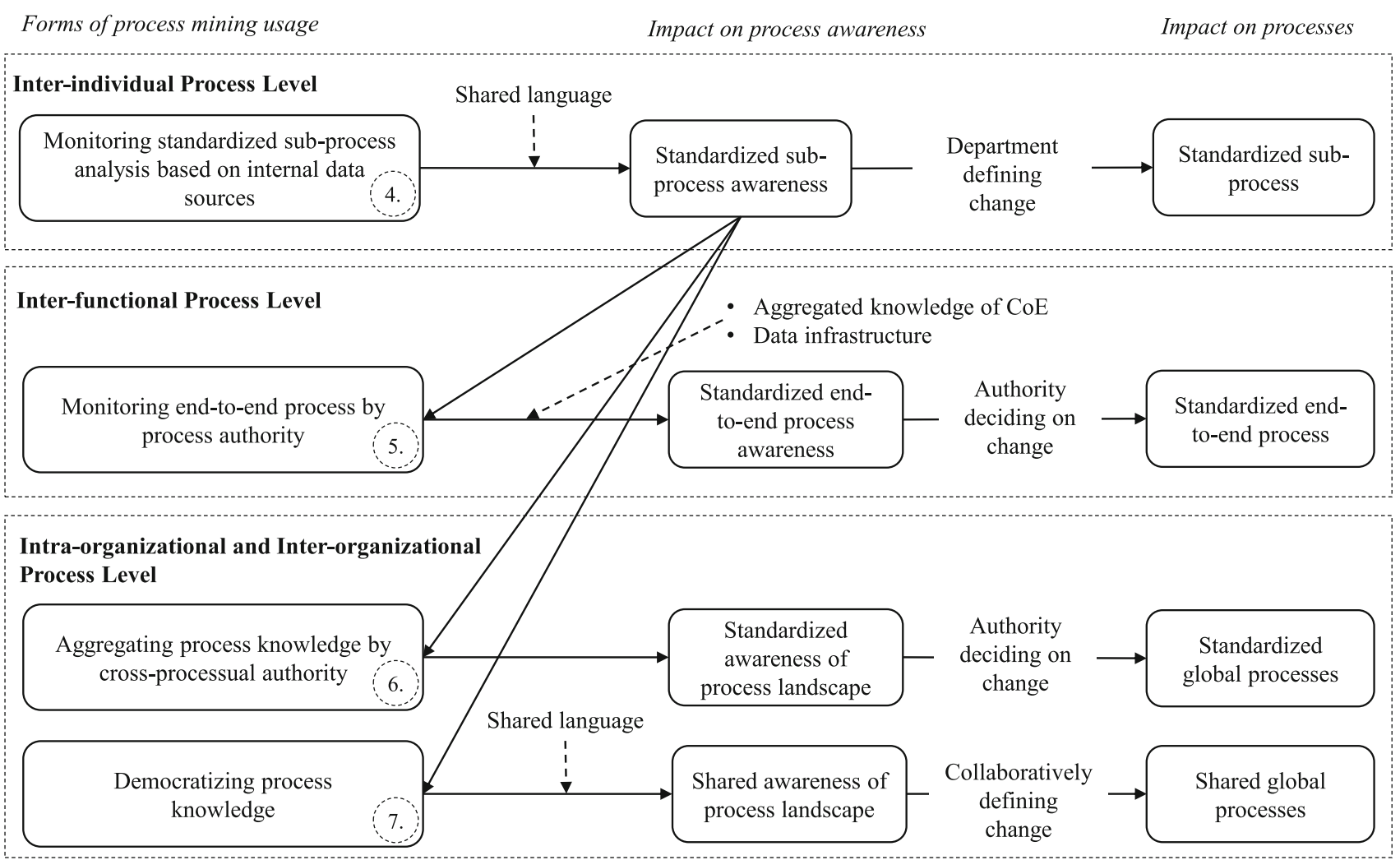

Fig. 2 Mechanisms of top-down monitoring leading to increased process awareness

problems, as observed in the example of ManuCorp where the departments remained limited to studying pre-defined criteria within their silos. Broadening this bounded usage to include the end-to-end process context requires managerial intervention.

In the fifth mechanism, process awareness on an interfunctional level is created through a process authority established by the management, such as process owners responsible for engaging stakeholders and acquiring data to facilitate end-to-end process mining analyses. An example is ManuCorp, where concurrent to the implementation of process mining, the management established the role of process owners responsible for involving end-to-end process stakeholders and defining standardized analyses to gain process transparency across divisional boundaries. Depending on the firm's data infrastructure, the implementation of the analyses is facilitated by centralized, standardized data sources. In addition, the CoE supports the identification and transformation of process data. After performing the analyses, the process owner communicates aggregated insights to the departments and finally decides on process changes. Thereby, the stakeholders involved in an end-to-end process, such as the lead-to-sales process at ManuCorp, are provided with a standardized process awareness by the process owner, contributing to a standardized process execution across departments. Yet, while process owners are responsible for the end-to-end process level, they are limited in their power and knowledge to optimize the overall process landscape.

Therefore, the sixth mechanism addresses the awareness of the firm's overall process landscape at the inter- and intra-organizational levels. This mechanism evolves as the management establishes a cross-processual authority, such as a CPO at DistriCorp or a Governance Board at ManuCorp, responsible for aggregating the departments' local process mining knowledge. For example, DistriCorp's CPO regularly meets with representatives from the departments to exchange the results of their process mining analyses. Note that, contrary to the role of a process owner, this authority acts on a cross-processual level, meaning that process mining insights are not only discussed within but across diverse end-to-end processes that connect different departments and organizations. Thereby, the cross-processual authority aggregates process mining knowledge that reflects the firm's overall process landscape. Through centrally aggregating individual departments' process mining findings and reflecting the synthesized knowledge into the silos, they develop a shared awareness of the process landscape that enables processual change towards standardization. However, as seen with ManuCorp, the resulting process knowledge is controlled by the process authority so that not everyone has equal access to it. 
Therefore, the seventh mechanism creates awareness of the firm's overall process landscape at the inter- and intraorganizational levels and democratizes access to it. An example is the central process mining platform introduced by ManuCorp's management that enables employees to access all process mining analyses. Facilitated by preceding data literacy training provided by the $\mathrm{CoE}$, employees can evaluate the analyses and build process awareness beyond their processual silos. As the process of building awareness is not controlled by a central authority, it emerges individually from the departments while employees interact with the process platform. Even though the process understanding might vary between departments, it is no longer informed only by individual perceptions but grounded on a unified fact base that reflects the global process landscape. We, therefore, expect a shared awareness of the firm's process landscape to emerge over time within and between departments which they draw on to inform and design shared global routines. We see this in the example of ManuCorp, where employees use the process platform to understand the global relationships between suppliers, customers, and production plants and express process optimization potentials.

\subsection{Theoretical Implications}

Overall, our research contributes towards understanding how organizations act upon the unprecedented transparency created through process mining (Grisold et al. 2020; Mendling et al. 2020) and how they leverage the transparency to benefit from increased process awareness (Eggers and Hein 2020). To this end, we identified seven mechanisms that enable organizations to achieve increased process awareness from process mining. Thereby, our study contributes to research on business process management and process mining in three ways.

First, our study contributes to research on business process management by revealing process mining as a new, data-driven way of creating process awareness. Creating process awareness throughout the organization is viewed as a major challenge, primarily due to a lack of a shared process language (Christiansson and Rentzhog 2019; Dumas et al. 2018) and difficulties in creating process transparency and a shared process understanding across organizational silos (McCormack and Rauseo 2005). While there are multiple techniques known from BPM research for creating process awareness, process mining is differentiated by its data-driven, automated discovery approach. The interview-based and workshop-based process discovery methods traditionally used in BPM (Dumas et al. 2018) serve to develop a common understanding and discover rationales behind certain actions, but at the same time they are at risk of resulting in subjectively influenced, incomplete process models (Rosemann 2006; Seethamraju and Marjanovic 2009). As evident from research on human memory and recollection, such procedures are prone to cognitive bias and-intentional or unintentional-omission (Okado and Stark 2003), which bears the risk of subjectively impacting or skewing the resulting process awareness. Even the evidence-based process discovery methods, such as the analysis of existent process documentation or the shadowing of process operators, depend on individual observations and potentially outdated or momentarily created material that usually reflects only a fraction of the firm's living process landscape (Dumas et al. 2018; Malinova and Mendling 2018). In that light, process mining can be understood as a technology-enabled evidence-based discovery method that relies on objective data to create process transparency on a firm's overall process landscape independent of subjective impressions-however, given that process activities are traced in corresponding IT systems (van der Aalst 2016). Drawing on this transparency, process stakeholders can engage in a dialogue to explain rationales or exchange experiences-similar to established BPM approaches-while relying on a current, objective fact base. Thereby, process mining can facilitate the emergence of a shared process language (Christiansson and Rentzhog 2019) in the firm by offering a standardized, objective reference frame when discussing processes. In addition, process mining supports the development of a shared process understanding (McCormack and Rauseo 2005) by providing an objective, up-to-date fact base that potentially reflects the firm's entire process landscape, which employees can jointly explore and discuss.

Second, our research reveals that while the use of process mining enables mechanisms for creating process awareness, the mechanisms and resulting type of awareness largely depend on the firm's chosen process mining governance approach, i.e., top-down or bottom-up driven governance. While previous research points towards the importance of adopting a structured process mining approach to achieve valuable and reliable process transparency (Aguirre et al. 2017; Mans et al. 2013), the overarching governance structures that enable firms to leverage such transparency for their benefit remained unknown (Mendling et al. 2020; vom Brocke et al. 2014). On the one hand, our study provides evidence that organizations are adopting a top-down process mining governance approach to further awareness and standardization of sub-processes as departments are required to adopt the technology for monitoring specified process KPIs. While that is valuable in the light of creating awareness for process performance within departments, the firms yet struggled with establishing the self-governed, exploratory use of process mining across functions to discover unknown process complications. One reason may be that employees had not 
been involved in the design and implementation of process mining analyses and thus were unaware of the technological capabilities-a complication that results in low perceived usefulness, which is known as a major factor influencing technology adoption in IS research (Venkatesh et al. 2003). In addition, this observation may be due to the sociological phenomenon known as the streetlight effect, which implies that humans tend to search where it is easiest and most obvious to look while neglecting the exploration of alternative effects (Newquist et al. 2015). Still, to advance end-to-end and global process awareness, the firms established central process mining authorities who aggregate, standardize, and communicate process knowledge across different functions. However, the resulting awareness might still be prone to the observational bias of the streetlight effect and is likely affected by the perception of the central process authority. Alternatively, the management encourages the autonomous, employee-driven development of a shared process understanding by democratizing access to process knowledge.

In addition, our study reveals that the bottom-up driven governance of process mining results in exploratory usage that enables firms to generate awareness on sub- and endto-end processes iteratively. For this approach to succeed, the technical and conceptual enablement of employees is critical to prepare them for using process mining and to act on its results. Similar observations on the role of education and enablement have been made in recent research on bottom-up driven, people-centric approaches to BPM that aim to include operational employees in understanding and transforming the firm's processes (Bruno et al. 2011; Prilla and Nolte 2012). Our study shows that when employees are enabled, for example, by a $\mathrm{CoE}$, the departments across the firm autonomously adopt process mining to analyze the sub-processes they carry out, which leads them to explore the further end-to-end process context they are embedded in. However, while they develop a shared understanding of the process, unbiasedly without prescribed KPIs to focus on, these efforts lack a coordinated approach to aggregate process knowledge on a global level. Thus, this governance approach causes the awareness resulting from process mining to persist fragmented across functions or end-to-end processes.

Third, while our study provides evidence of how the unbiased, objective transparency created by process mining enables increased process awareness, our study also points to the importance of balancing the social complications of increased transparency, such as employees' fear of surveillance. These findings resonate with previous research in the field of BDA that hints towards the regulatory and organizational backlashes that firms experience through data-driven transparency (Günther et al. 2017; Richards and King 2013). To address these complications, technological measures have been proposed to ensure that data privacy and security are maintained, for example, by anonymizing sensitive data before analyzing it or ensuring restricted access through encryption and authentication (Gahi et al. 2016). On the same note, research on process mining has recently yielded the first advancements toward developing privacy-preserving mining approaches (Mannhardt et al. 2019). Our findings complement these technological measures by shedding light on measures that firms employ to manage challenges resulting from datadriven transparency, such as ensuring democratic and transparent access to analyses or educating employees about data for and functionalities of process mining analyses.

\subsection{Practical Implications}

In addition, our research has several implications for practitioners. First, by analyzing four different cases of organizational process mining usage, we provide practitioners with an overview of how transparency created by process mining can be leveraged for realizing benefits depending on the organizational and industry context. These reflections can serve as a starting point for discovering valuable process mining opportunities. Second, our findings acknowledge the very real challenge faced by organizations that struggle to increase process mining adoption due to transparency-induced skepticism and restraint in the workforce. We point towards measures to address these concerns that have proven valuable in the context of the four studied organizations. Third, our findings sensitize practitioners to different measures that can be taken to increase organizational process awareness on the sub-process, end-to-end process, or process landscape level. Different measures with different advantages and disadvantages become relevant depending on the process mining governance approach chosen, i.e., a top-down or bottom-up driven scenario.

\section{Limitations and Conclusion}

To conclude, we acknowledge that our research is subject to several limitations. First, a potential limitation is the retrospective bias of informants regarding their past activities of implementing and using process mining. However, as displayed in Table 2, the emerging mechanisms were triangulated from multiple archival data sources and from the interviews to provide rich descriptions of how the firms' process mining use led to process awareness. Second, we focused our study on the implications of process mining for process awareness as a critical antecedent to process orientation and optimization. Process 
orientation, however, is a complex phenomenon that requires further organizational changes, such as a processoriented structure and management. While not within the scope of our study, we consider it a valuable avenue for future research to explore how process mining impacts further dimensions of process management and optimization. For example, our study hints at the implications of process mining for institutionalized organizational structures by establishing process-oriented structures, such as process owner roles. Third, our research is subject to contextual limitations as we studied the emergence of process awareness with regards to medium-sized and large companies with headquarters in Western Europe. While we included a diverse set of companies of different sizes, industries, and process contexts, ranging from analyzing internal production processes to digital customer journeys, our results might be limited in transferability to other settings. For example, national, organizational, and team culture are known to impact a firm's transition towards process awareness (vom Brocke and Sinnl 2011). Therefore, the application of process mining in other cultural or industry contexts, such as the regulated context of public administration, might require alternative mechanisms to foster process awareness.

While process mining presents firms with the opportunity to generate unparalleled transparency regarding their business processes and foster process awareness, organizations still struggle to realize these potentials in practice. This study unravels seven mechanisms that enable firms to generate different forms of process awareness by using process mining, depending on the chosen governance approach. This broadens our understanding of how organizations engage with transparency from process mining, create process awareness and, ultimately, achieve lasting process optimization.

Funding Open Access funding enabled and organized by Projekt DEAL.

Supplementary Information The online version contains supplementary material available at https://doi.org/10.1007/s12599021-00715-x.

Open Access This article is licensed under a Creative Commons Attribution 4.0 International License, which permits use, sharing, adaptation, distribution and reproduction in any medium or format, as long as you give appropriate credit to the original author(s) and the source, provide a link to the Creative Commons licence, and indicate if changes were made. The images or other third party material in this article are included in the article's Creative Commons licence, unless indicated otherwise in a credit line to the material. If material is not included in the article's Creative Commons licence and your intended use is not permitted by statutory regulation or exceeds the permitted use, you will need to obtain permission directly from the copyright holder. To view a copy of this licence, visit http://creativecommons. org/licenses/by/4.0/.

\section{References}

Agrawal R, Gunopulos D, Leymann F (1998) Mining process models from workflow logs. In: Schek H-J et al (eds) Advances in database technology. Springer, Heidelberg, pp 467-483

Aguirre S, Parra C, Sepúlveda M (2017) Methodological proposal for process mining projects. Int $\mathrm{J}$ Bus Process Integr Manag 8(2):102-113

Augusto A, Conforti R et al (2019) Automated discovery of process models from event logs: review and benchmark. IEEE Trans Knowl Data Eng 31:686-705

Bruno G, Dengler F et al (2011) Key challenges for enabling agile BPM with social software. J Softw Maint Evol Res Pract 23(4):297-326

Christiansson M-T, Rentzhog O (2019) Lessons from the "BPO Journey" in a public housing company: toward a strategy for BPO. Bus Process Manag J 26(2):373-404

Corallo A, Margherita A, Scalvenzi M, Storelli D (2010) Building a process-based organization: the design roadmap at Superjet International. Knowl Process Manag 17(2):49-61

Dakic D, Stefanovic D, Cosic I, Lolic T, Medojevic M (2018) Business process mining application: a literature review. In: Proceedings of the 29th DAAAM international symposium. Vienna, Austria

Danilova KB (2019) Process owners in business process management: a systematic literature review. Bus Process Manag J 25(6): 1377-1412

Davenport TH (2020) Process mining: from analytics to action. https://www.forbes.com/sites/tomdavenport/2020/06/30/processmining-from-analytics-to-action/?sh=4cdd206d46f5. Accessed 1 Apr 2021

Davenport TH, Short JE (1990) The new industrial engineering: information technology and business process redesign. Sloan Manag Rev 31(4):11-27

Dubé L, Paré G (2003) Rigor in information systems positivist case research: current practices trends, and recommendations. MIS Q 27(4):597-635

Dumas M, Rosa ML, Mendling J, Reijers H (2018) Fundamentals of business process management, vol 2. Springer, Heidelberg

Eggers J, Hein A (2020) Turning big data into value: a literature review on business value realization from process mining. In: Proceedings of the 28th European conference on information systems (ECIS), An Online AIS Conference

Eisenhardt KM (1989) Building theories from case study research. Acad Manag Rev 14(4):532-550

Eisenhardt KM, Graebner ME (2007) Theory building from cases: opportunities and challenges. Acad Manag J 50(1):25-32

Farid NF, De Kamps M, Johnson OA (2019) Process mining in frail elderly care: a literature review. In: Proceedings of the 12th international joint conference on biomedical engineering systems and technologies (BIOSTEC 2019). Prague, Czech Republic

Gahi Y, Guennoun M, Mouftah HT (2016) Big data analytics: security and privacy challenges. In: Proceedings of the 2016 IEEE symposium on computers and communication (ISCC). Messina, Italy

Ghazal MA, Ibrahim O, Salama MA (2017) Educational process mining: a systematic literature review. In: Proceedings of the 2017 European conference on electrical engineering and computer science (EECS). Bern, Switzerland 
Gioia DA, Corley KG, Hamilton AL (2013) Seeking qualitative rigor in inductive research: notes on the Gioia methodology. Organ Res Meth 16(1):15-31

Glaser B, Strauss A (1967) Grounded theory: the discovery of grounded theory. Aldine, Chicago

Grisold T, Mendling J, Otto M, vom Brocke J (2020) Adoption, use and management of process mining in practice. Bus Process Manag J 27(2):369-387

Günther WA, Rezazade Mehrizi MH, Huysman M, Feldberg F (2017) Debating big data: a literature review on realizing value from big data. J Strateg Inf Syst 26(3):191-209

Hammer M, Stanton S (1999) How process enterprises really work. Harv Bus Rev 77(6):108-118

Jans M, Alles MG, Vasarhelyi MA (2014) A field study on the use of process mining of event logs as an analytical procedure in auditing. Account Rev 89(5):1751-1773

Jokonowo B, Claes J, Sarno R, Rochimah S (2018) Process mining in supply chains: a systematic literature review. Int J Elect Comput Eng 8(6):4626-4636

Jones M (2019) What we talk about when we talk about (big) data. J Strateg Inf Syst 28(1):3-16

Kerremans M (2019) Market guide for process mining. Gartner Report

Kohlbacher M (2010) The effects of process orientation: a literature review. Bus Process Manag J 16(1):135-152

Kohlbacher M, Gruenwald S (2011) Process orientation: conceptualization and measurement. Bus Process Manag J 17(2):267-283

Konrad A (2021) Celonis raises $\$ 1$ billion at $\$ 11$ billion valuation, making it New York's - and Germany's - most valuable startup. https://www.forbes.com/sites/alexkonrad/2021/06/02/celonis-pro cess-mining-raises-at-11-billion-valuation/. Accessed $11 \mathrm{Jul}$ 2021

Leyer M, Hirzel A-K, Moormann J (2018) Achieving sustainable behavioral changes of daily work practices. Bus Process Manag $\mathrm{J}$ 24(4):1050-1068

Malinova M, Mendling J (2018) Identifying do's and don'ts using the integrated business process management framework. Bus Process Manag J 24(4):882-899

Mannhardt F, Koschmider A, Baracaldo N, Weidlich M, Michael J (2019) Privacy-preserving process mining. Bus Inf Syst Eng 61(5):595-614

Mans R, Reijers H, Berends H, Bandara W, Rogier P (2013) Business process mining success. In: Proceedings of the 21st European conference on information systems (ECIS). Utrecht, The Netherlands

McCormack K, Rauseo N (2005) Building an enterprise process view using cognitive mapping. Bus Process Manag J 11(1):63-74

Mendling J, Pentland BT, Recker J (2020) Building a complementary agenda for business process management and digital innovation. Eur J Inf Syst 29(3):208-219

Miles MB, Huberman MA (1994) Qualitative data analysis: an expanded sourcebook. Sage, Thousand Oaks

Myers MD, Newman M (2007) The qualitative interview in IS research: examining the craft. Inf Organ 17(1):2-26
Newquist DD, DeLiema M, Wilber KH (2015) Beware of data gaps in home care research: the streetlight effect and its implications for policy making on long-term services and supports. Med Care Res Rev 72(5):622-640

Okado Y, Stark C (2003) Neural processing associated with true and false memory retrieval. Cogn Affect Behav Neurosci 3(4):323-334

Prilla M, Nolte A (2012) Integrating ordinary users into process management: towards implementing bottom-up, people-centric BPM. In: Ilia Bider TH et al (eds) Enterprise, business-process and information systems modeling. Springer, Heidelberg, pp 182-194

Reder B, Freimar AJ, Holzwart G, Mauerer J, Schonschek O, Schweizer M (2019) Studie Process Mining \& RPA 2019. IDG Research Services Report

Richards NM, King JH (2013) Three paradoxes of big data. Stanf Law Rev Online 66:41-46

Rosemann M (2006) Potential pitfalls of process modeling: Part A. Bus Process Manag J 12:377-384

Sarker S, Chatterjee S, Xiao X, Elbanna A (2019) The sociotechnical axis of cohesion for the IS discipline: its historical legacy and its continued relevance. MIS Q 43(3):695-720

Seethamraju R, Marjanovic O (2009) Role of process knowledge in business process improvement methodology: a case study. Bus Process Manag J 15(6):920-936

Thiede M, Fuerstenau D, Bezerra Barquet AP (2018) How Is process mining technology used by organizations? A systematic literature review of empirical studies. Bus Process Manag J 24(4):900-922

Turner CJ, Tiwari A, Olaiya R, Xu Y (2012) Process mining: from theory to practice. Bus Process Manag J 18(3):493-512

van Assen M (2018) Process orientation and the impact on operational performance and customer-focused performance. Bus Process Manag J 24(2):446-458

van der Aalst W (2016) Process mining. Data science in action, 2nd edn. Springer, Heidelberg

van der Aalst W, Adriansyah A et al (2011) Process mining manifesto. In: Daniel F et al (eds) Business process management workshops. Springer, Heidelberg, pp 169-194

Venkatesh V, Morris MG, Davis GB, Davis FD (2003) User acceptance of information technology: toward a unified view. MIS Q 27(3):425-478

vom Brocke J, Mendling J (2018) Business process management cases. Digital innovation and business transformation in practice. Springer, Cham

vom Brocke J, Sinnl T (2011) Culture in business process management: a literature review. Bus Process Manag J 17(2):357-378

vom Brocke J, Schmiedel T, Recker J, Trkman P, Mertens W, Viaene S (2014) Ten principles of good business process management. Bus Process Manag J 20(4):530-548

Yin RK (2014) Case study research: design and methods, 5th edn. Sage, Thousand Oaks 